\title{
Study on Implementation Effect of China's Teenager Campus Football Activities and Evaluation Mechanism
}

\author{
Xiong Wang, Wenkun Tang, Chunwang Pu \\ College of Physical Education, Yuxi Normal University, Yuxi Yunnan, 653100, China
}

Keywords: Sports level, Teenagers, Football activities, Implementation effect

\begin{abstract}
As China's economic strength has been increasing, various sports activities attach much attention at home and abroad, football in China has a long history, which is a symbol of a whole nation constitutions and literacy, as well as the overall strength of the relationship between the country's image, and continuously improve football is an increase in the level of country's soft power. Young people are the reserve force of football, good youth football training and education related to the future development trend of China's football. This article will analyze teenagers' campus football activities implementation evaluation effectiveness, aimed to provide some basis for youth football training.
\end{abstract}

\section{Introduction}

Affected humanities and natural conditions, there is the overall physical and mental qualities and a wide gap between foreign football players in many international soccer matches in our country can not achieve satisfactory results. In order to better carry out my football career, training more strong overall quality footballer has become an important work of the Football Association and the relevant departments. Even our country is a populous country, football has a long history, but in the culture of youth football players started late, and many foreign countries football is very big focus on training young children, football, laying the foundation for the future development of football. Must comply with the development trend of the times, focus on young children football training, and constantly improve their interest in football, to attract more young people to participate in football activities, enhance physical fitness, temper will play in the promotion of its football career development of value.

\section{Status of China's teenager campus football activities}

\section{Lack of fields and fare}

This paper examines 30 high school, 100 junior secondary school, and 200 ordinary primary schools, to fully investigate these schools with sports facilities, the study found that 13.5 percent of 12 to carry out a standard soccer match only the total primary and secondary schools venue proportion $200 \mathrm{~m}$ or $300 \mathrm{~m}$ of $50.7 \%$, junior high football field than the major construction, but most urban high school students to carry out only eight matches following a football match, in view of the limited space, 12-a-side football game a bit crowded. The site below $200 \mathrm{~m}$ schools only 30.14 percent, mostly students. With the further expansion of enrollment, the burden of stadium construction is growing, to get students to run freely in the football field and facilities necessary to increase capital investment, but many schools said funds and shortage of land, has not been able to build a fully equipped football pitch.

\section{Lack of teachers resources}

The relative lack of awareness of adolescent football, has been covered on television and on the books only, which requires teachers to teach students to enhance the recognition of football, "a great day" which words reflect the importance of teachers, teacher teenagers campus football activities, played the role of enlightenment and guidance. But most school PE teachers to assume all of the sports teaching, including soccer, learning sports and more, not just a focus on football sports curriculum, and teachers could not hire professional football, not soccer skills Specialized Training Student . By investigating several school PE teachers special skills found only $8 \%$ of teachers 
Football proportion, and special teacher basketball, volleyball and more less than 6\%, a direct impact on the students' interest in the sport, limiting the quality of its sports culture [1].

\section{Safety issues}

Student safety and security are issues of common concern parents and teachers, but also the foundation of the school to organize sports activities. If the student is any mishap occurs in school sports activities, the school will inspire conflict with parents, through more than a few different sports school survey found that the number of injured to 254 football, 120 basketball the number of injured, gymnastics 70 people, Athletics 40, volleyball 18 people. Thus, football is the most prone to injury secure sports, accounting for more than $40 \%$ of the total number of injured. Thus, many students are afraid of football, for football sense of conflict, it is a sport of its own nature and characteristics of the decision, soccer field needs to run, snatch, collision, the atmosphere is very intense, the students will slip a little was hit or injure others, you need to have good skills, physical fitness and skill, but also a self-protection awareness, but many students lack these skills and awareness, very vulnerable to injuries.

\section{Status of football into campus}

\section{Schools participated}

The article mentioned a few schools analyze football into the campus activities carried out case study. Schools are in accordance with the above "National Youth campus football implementation plan" requirements in the implementation of football-related work activities and the establishment of a special agency, and constantly improve the football field of facilities, equipment and the like; efforts to organize a good instructor, training for these teachers education, the ability to enhance their business; more preparations and organization of football matches, football on campus influence enhancement; football more than the increase teaching hours, to ensure that there are two hours of football a week teaching, encourage all students to participate Soccer teaching activities. With the gradual implementation of the implementation of the above work, a lot of teenagers said several schools were actively involved in the football event, with the media and the football games live abroad, make football take root in the minds of students, teachers and students to participate in football picture increase. Carry out a variety of football leagues, for example, 2013--2014 annual tournament in October 16, 2013 officially began, until the end of May 2014 ended. Take all weekend game system, with the away games. Primary divided into specific groups (1-3), (4-6) Grade men's competition is divided into A and B groups, the same as the women's race; junior men's race, the women's race, high school male and female group competition, the participating students a total of 1000. Football into the campus activities in many schools up and expanding national strategy of local, layout and scale of the campus football has also increased, more and more young people involved, to enjoy the fun of football [2].

\section{League system of football into campus}

Football into the campus activities undertaken league system mode is divided into campus and off-campus football league football league. Take away round-robin competition, selected eight players to play in elementary school group, selected four off the bench, while playing high school athletes selected group of 12 people, nine off the bench. Primary predetermined game time is 1 hour 30 minutes, the first half and the second half, each 45 minutes, intermission time is not more than 20 minutes. Make sure every field there are three bench players, so the game can be continued. Each team wins game 5 points, flat-field 2 points, negative a no points, ranked according to score, ranking by the outcome of the game, goal difference and goals total number of decisions, many rank on the front, if these indicators then draw lots to decide the same rank.

\section{Publicity of football into campus}

Football into the campus is no longer a novelty, the purpose is to train students motivated and persistent thoughts, more support for students will be involved in football as a lifelong sport and attract more social groups concerned carry out youth campus football activities. This activity continues to increase publicity, will set up a good example. So that the whole community to see the future development of football hope, for people to bring more expectations. Since 2010, many 
universities have begun to pay attention to football into the campus, and increase the call for this activity and propaganda, the effect is significant. From the current point of view of football into the campus activities, there are still a lot of grounds to make up, the atmosphere of competition is not fierce, competition rules still need to improve [3].

\section{Implementation effect of campus into campus}

\section{Implementation effect of football into campus for schools}

For schools participating in football into the campus activities, the role of decision-making and leadership at all levels to guide teachers play a very important and directly related to the quality and effectiveness of this activities, the faculty, excellent facilities, sufficient funds are activities to be undertaken by the foundation. Thus, through the communication of all levels of leadership and teachers found that, in vigorously promote the call, many leaders expressed their recognition and support of the activities have a high degree of enthusiasm. Survey shows that primary and secondary school "very supportive" accounting for 35.2\%, 30.45\%; "general support" accounted for 24.2\%, 33.5\%; "more supportive" accounted for 5.6\%, 11.4\%. Thus, most of the schools attach more emphasis on football into the campus. Only for the recognition and support of the school, football can be successfully carried out. But because of the lack of attention of higher education authorities, local education department does not attach importance on it, the jurisdiction of the regional school leaders also the general attitude. Junior high school students forced their studies and academic pressure, that cultural lesson is teaching focus, football does not need to put too much energy and financial resources, thereby actively in activities extent, the students' academic stress is relatively small, a variety of sports activities Learn more attractive than knowledge, fitness and more students and parents by the school concerned, thus, to carry out primary school football activities more viable, more parties to support [4].

\section{Effect of football into campus for parents}

Currently, the high school students and primary school students cannot carry out activities alone, ideology also in maturity and development stage, the activities required under the custody of parents and teachers, thereby, the parents of school football into the campus of awareness, held attitude will directly determine whether students can continue to participate in football activities. Parents' factors become key factors. Randomly selected in each of the 150 school students, its research, very much support there is 50 , there are 42 more support, generally supports 35,13 are not supported, the proportion was as follows: $33.3 \%, 28 \%, 23.3 \%, 0.86 \%$. Very supportive of the child to participate in football activities, the majority of parents, only a small portion of the parents do not support children to participate in football activities, it can be seen, parents generally believe that the child is more important than physical achievement, only a small portion of parents do not want students to participate in football activities that football no development, learning time delay, fearing accidental injury in the fierce competition. Many problems of examination-oriented education so that parents fear, worry sports hinder children survive the growing season, viewed from the perspective of parents, the children are interested in football, but football is not optimistic about the development of China, the students in order to have development. The main reason is the parents do not realize football activities on promoting the role of student, school and teachers did not get through football activities carried out to the parents of the students' sense future growth, but most parents deal with the relationship between football and learning has their own practices, who can understand the attitude.

\section{Students survey result of football into campus}

Football career to continue its steady development must continue the training of reserve forces, which is also the objective requirement such circumstances, but to participate in football training and forced schools and parents are reluctant to see the football into the campus activities of mind is Students interested in football, so that students can consciously participate in activities, rather than passive, but also as an important way to reduce "fraught", "worthless" and other rumors appear. Sports motivation is intrinsic factors involved in physical exercise, students can actively participate in sports activities is inseparable from internal motivation of catalysis. Various intrinsic motivation mutual assistance, but also by the coordinating role of individual differences, gender, age. The survey 
found that 52.4 percent of the students are not involved in football because I like football, there are $35.6 \%$ of the students because they can participate in football activities to keep fit, and $12 \%$ of students hold soccer star carries the dream of participating in football activities, hoping that one day It could become a David Beckham, Cristiano Ronaldo as brilliant football star. School football instructor in the school selection can attract more talented students to participate in football, also accounted for a certain percentage. Fully understand the students to participate in football activities in mind will allow students to better participate in football activities [5].

Physical survey data reflects implementation effect of football on middle and primary students

Football into the campus activities for students height, body mass index have a certain effect, the nutritional status of the person can BMI index, body symmetry degree, reflected the level of development, practice shows that many students participate in soccer sports can improve overall adolescent physique, FIFA as a health "guardian", playing football for an hour a day to promote adolescent health and development. In addition, actively participate in football but also to improve people's resistance and immunity, studies have shown that regular football can reduce the incidence of cardiovascular and cerebrovascular disease, hypertension, and football players have more than $80 \%$ of the time heart rate of $60 \%$. become to lose weight, enhance effective means body metabolism.

\section{Conclusions}

Our country has always been a sports power, won the laudable achievements in international competitions for all kinds of sports, but football has not been able to develop, the lack of sufficient experience and methods of cultivation on domestic football players, and the overall quality of our football players low, a lot of factors that hinder the Chinese football to the world. This paper describes the youth football into the campus activities status quo, and found a lot of problems, youth football into the campus football culture is the key to the reserve forces, the effect of starting the implementation of research activities will benefit from all angles to get the parties to support, so that more cultured footballer effectiveness and has targeted.

\section{Acknowledgments}

This paper is a key project of Yunnan Province Department of Education Fund for Scientific Research, project name: Yunnan Province teenager campus football investigation, NO: 2015Z177; also it is a youth teacher Yuxi Normal College Young Teachers' Training funded projects.

\section{References}

[1] Li Kegang. Empirical study on teenagers campus football value identity - Based on the investigation of Henan provincial school football layout. Henan University, 2014.

[2] Li Jixia, He Zhilin, Dong Zongming. National youth campus football bottlenecks and breakthrough strategy. Journal of Shanghai University of Sports,2012,36(3):83-86.

[3] Zhang Xiaodong. An Empirical Study of Youth Campus Football Activities in Dalian City - A Case Study of Dalian Thirteenth Middle School. Junior Sports, 2013(4):137-138.

[4] Zheng Qi, Yu Yong, Chen Huan. Survey of national teenager campus football coaches and countermeasures Research of Academy Education, 2012 (9): 188-189.

[5] Wang Ge. Study on the status, problems and countermeasures of China's campus football activities. Journal of Shenyang Institute of Physical Education, 2011,30(2):99-102. 